\title{
The Mental Health (Amendment) Bill-An Oxford Conference
}

\author{
Deenash I. Khoosal, Registrar, Warneford Hospital, Oxford
}

A conference on the proposed Amendment to the Mental Health Act was held at Oxford on 1 October, 1982, under the auspices of the British Psychological Society.

The first session started with a paper by Dr John Hamilton. He traced the path that mental health legislation has taken from the Mad Houses Act (1744), through the Lunacy Act (1890) to the present Mental Health Act (1959). The proposed amendment (Bulletin. September 1982, 158-59) was then outlined. Dr Hamilton felt that it was appropriate that mental health legislation should keep abreast with changing public attitudes. The proposed amendment was eventually determined by wide public consultation and much behind-the-scene negotiations. The final draft he felt was 'like a house of cards'-any further changes might cause it to collapse.

Dr Hamilton saw the Bill as moving towards 'legalism', but he was determined that medical responsibility should not be abdicated. A solicitor in the audience pointed out that valid consent for treatment for a patient compulsorily detained was a legal matter and as such, was best dealt with by the courts. Members of the legal profession present did not think that the Bill was a move towards 'legalism'. Larry Gostin (the legal director of MIND) smiled at this point which prompted me to do a quick tally of the 100 listed participants: there were 26 members of the legal profession and only 18 from the medical profession. Statistics can be misleading, but perhaps there was something significant in Mr Gostin's smile?

Dr Ron Blackburn (Chief Psychologist, Park Lane Hospital) then delivered a paper entitled 'Are personality disorders treatable?' He felt that if they were untreatable, they should not necessitate compulsory admission and that the courts were better able to manage these individuals than the mental hospitals. He considered three issues: firstly, there was the problem of definition of a disorder vs. disease -each with its own implications; secondly, came the problem of classification and the differences between DSM-III and ICD9; thirdly, came the available forms of treatment and their efficacy. This led Dr Blackburn to conclude that personality disorders were probably treatable but that the definitive answer was not yet known.

Dr Jill Peay (Psychologist, Research Officer at the Centre for Criminological Research) devoted her talk to the workings of the current Mental Health Review Tribunals and turned to consider whether the new MHRTs would be an improvement on those functioning under the 1959 Act. Her research had found that the decisions of MHRTs varied tremendously from region to region. In general Tribunals often did not know their powers, tended to be overcautious about discharge, and were more sympathetic to the psychiatrist's viewpoint, thereby converting 'courts into clinics'. She applauded the changes that the Amendment proposed: in particular the greater openness and accountability as previously none was obtainable from the
Secretary of State. Dr Peay felt that there was significant scope for improvement and was convinced that MHRTs should obtain feedback about their functioning in order to improve efficiency. A lively discussion was initiated by a chairman of a MHRT. He felt that under the 1959 Act, MHRTs could only say 'yes' or 'no' to applications for discharge from Section by restricted patients. MHRTs under the Amendment would be able to say 'yes, but tomorrow'. He felt unhappy that MHRTs were given responsibility but no real power. Other chairmen added that the provision of after care for detained patients was a valuable addition to the Bill, but that the lack of resources would reduce it to a farce.

Bernard Kat (Chairman of the BPS Division of Clinical Psychology) in his paper pointed out that psychological treatments do not appear to be represented in the Bill. At the time of the 1959 Act, psychologists were mostly employed in improving diagnostic accuracy for psychiatrists. Since then, however, psychologists had moved on to treatment. The Bill implied that a psychologist was under responsibility to the consultant, while psychologists saw their primary accountability as being to the patient. Psychologists present were concerned that a medical officer could decide on psychological treatments, as well as give 'expert opinion' on whether a patient was likely to benefit from this treatment. The Amendment in his view denied recognition of the work of psychologists.

Larry Gostin (MIND) spoke on 'Legal and policy implications of the Act'. He agreed that the Bill appeared to move towards 'legalism' but in effect offered no meaningful protection to a patient, as second opinions were purely medical. The psychiatrist was not bound by law to take into account the lay opinion advocated in the Bill. He added that legal assistance by way of representation had been incorporated in the Bill for helping detained patients appealing to the MHRTs. He had been reassured by the Law Society that this would take no longer than one week to arrange. He also urged MHRTs not to grant adjournment of a hearing in an attempt to prevent unnecessary prolongation of appeals.

Both Mr Gostin and Dr Hamilton seemed to agree on regarding the new Bill as an improvement on the 1959 Act. The main advantages were: (i) Commissioners for Mental Health; (ii) increase in the number of opportunities for patients to appeal to MHRTs; (iii) consent for treatment and the need for second opinions for certain treatments. Certain inconsistencies persist, e.g. after care for detained but not for voluntary patients.

My own feeling is that this Bill will have far reaching influences on the practice of psychiatry and the legal profession and might affect the cases currently before the European Court of Human Rights. The implementation of its contents will be initially fraught with difficulties, but a well functioning multidisciplinary team and close liaison with MHRTs and the legal profession will ensure a fair deal for the small percentage of psychiatric patients needing compulsory care. 